\title{
Fabrication and Evaluation of N-Channel GaN Metal-Oxide-Semiconductor Field-Effect Transistors Based on Regrown and Implantation Methods
}

\author{
Huu Trung Nguyen *, Hisashi Yamada $₫$, Toshikazu Yamada, Tokio Takahashi and \\ Mitsuaki Shimizu \\ GaN Advanced Device Open Innovation Laboratory (GaN-OIL), National Institute of Industrial Science and \\ Technology (AIST), Nagoya 4648601, Japan; hisashi-yamada@aist.go.jp (H.Y.); toshi.yamada@aist.go.jp (T.Y.); \\ tokio-takahashi@aist.go.jp (T.T.); mitsu.shimizu@aist.go.jp (M.S.) \\ * Correspondence: nguyen.trung@aist.go.jp
}

Received: 2 January 2020; Accepted: 13 February 2020; Published: 18 February 2020

\begin{abstract}
We have demonstrated the enhancement-mode n-channel gallium nitride (GaN) metal-oxide field-effect transistors (MOSFETs) on homoepitaxial GaN substrates using the selective area regrowth and ion implantation techniques. Both types of MOSFETs perform normally off operations. The GaN-MOSFETs fabricated using the regrowth method perform superior characteristics over the other relative devices fabricated using the ion implantation technique. The electron mobility of $100 \mathrm{~cm}^{2} / \mathrm{V} \cdot \mathrm{s}$, subthreshold of $500 \mathrm{mV} / \mathrm{dec}$, and transconductance of $14 \mu \mathrm{s} / \mathrm{mm}$ are measured in GaN-MOSFETs based on the implantation technique. Meanwhile, the GaN-MOSFETs fabricated using the regrowth method perform the electron mobility, transconductance, and subthreshold of $120 \mathrm{~cm}^{2} / \mathrm{V} \mathrm{s}, 18 \mu \mathrm{s} / \mathrm{mm}$, and $300 \mathrm{mV} / \mathrm{dec}$, respectively. Additionally, the MOSFETs with the regrown $\mathrm{p}-\mathrm{GaN}$ gate body show the $\mathrm{I}_{\mathrm{on}} / \mathrm{I}_{\text {off }}$ ratio of approximately $4 \times 10^{7}$, which is, to our knowledge, among the best results of GaN-MOSFETs to date. This research contributes a valuable information for the design and fabrication of power switching devices based on $\mathrm{GaN}$.
\end{abstract}

Keywords: gallium nitride; metal-oxide field-effect transistors; fabrication

\section{Introduction}

Gallium nitride $(\mathrm{GaN})$ possesses such extraordinary characteristics as high breakdown electric field $(3 \mathrm{MV} / \mathrm{cm})[1]$, high saturation velocity $\left(1.4 \times 10^{7} \mathrm{~cm} / \mathrm{s}\right)[1]$, high electron mobility, and good thermal conductivity $(\sim 100 \mathrm{~W} / \mathrm{m} \cdot \mathrm{K})[1]$, thus emerging as one of the most promising materials for next generation power switching devices. Among GaN-based transistor structures, heterostructure field-effect transistors (HFETs) based on AlGaN/GaN heterojunction have been widely used for high-power and high-frequency applications owing to the high electron mobility deriving from the two-dimensional electron gas (2DEG) source. However, because HFETs operate at the normally on mode, there are many significant disadvantages, such as large leakage current, high power consumption in their analog and/or power applications. In order to demonstrate normally off GaN-based HEMTs, several approaches have been proposed. In general, a thin $\mathrm{AlGaN}$ barrier layer with a low $\mathrm{Al}$ concentration is usually used to achieve the 2DEG depletion region in normally off GaN-based HEMTs. Because the depletion of the 2DEG channel must be formed under the gate, the recession structure of the AlGaN barrier layer has been considered as one of effective solutions for normally off GaN HEMTs [2]. However, an accurate control of the AlGaN etching technology is highly required in this method. Moreover, the damages derived from the etching process probably increase the gate leakage current and hysteresis of threshold voltages. Recently, p-GaN (or p-AlGaN) layer on the 
$\mathrm{AlGaN} / \mathrm{GaN}$ heterostructure has been used as a promising approach to demonstrate normally off GaN-based HEMTs [3,4]. However, this structure is more complicated than previous candidates.

To solve this issue, approaches to use GaN-based metal/oxide/semiconductor field-effect transistors (MOSFETs) have been usually proposed by many researchers [5-13]. GaN-MOSFET is an ideal candidate to overcome the weaknesses of GaN-HFET owing to its large voltage sweep range, low gate leakage currents, and structure simplicity. Additionally, an enhancement-mode operation of $\mathrm{n}$-channel GaN-MOSFETs is crucial in avoiding the turn-off failure for the circuit safety of the integrated circuit (IC) applications. Not only the threshold voltage control so that the GaN-based MOSFETs perform the normally off characteristic, but also the low on-resistance is very important for transistors designed for power switching applications. The on-resistance is significantly affected by the channel electron mobility. A mobility of beyond $100 \mathrm{~cm}^{2} / \mathrm{V} \cdot \mathrm{s}$ is considered as a standard to obtain the on-resistance of $1 \mathrm{~m} \Omega \cdot \mathrm{cm}^{2}$, which is required for recent power IC systems [9].

The quality of GaN films, treatment of gate dielectrics, structural optimization, and relative fabrication processes are among crucial issues to optimize the n-channel GaN-MOSFETs with the high electron channel mobility, low interface state density, low gate leakage current and large $\mathrm{I}_{\mathrm{on}} / \mathrm{I}_{\text {off }}$ properties [11-21]. One of the most essential points is the formation of the high-quality GaN-channels (S/G/D regions). Recently, implantation and regrowth are the most common methods to produce high-quality n- and p-doped GaN. Many researchers have solely evaluated the quality of $n$ - and p-GaN layers produced by the implantation and epitaxial growth $[22,23]$. However, diverse applications of these methods to fabricate actual GaN-MOSFETs have not been fully explored yet. For instance, the advantages and disadvantages of GaN-MOSFETs fabricated using both methods still remain unclear. Another issue of fabricating high-performance n-channel GaN-MOSFETs is the interface state density between dielectrics and semiconductors. Various dielectrics, such as $\mathrm{SiO}_{2}, \mathrm{Al}_{2} \mathrm{O}_{3}, \mathrm{SiN}_{\mathrm{x}} \mathrm{AlSiO}_{\mathrm{x}}, \mathrm{HfO}_{2}$, etc., have been widely used in general MOSFETs. Among them, $\mathrm{Al}_{2} \mathrm{O}_{3}$ is considered as an excellent material owning to the high dielectric constant (8-10), good breakdown field ( $>1 \mathrm{MV} / \mathrm{cm})$, and large bandgap (6-8 eV). Because of the capability to synthesize precisely the thickness and pinhole-free thin film with accurate monolayers, the atomic layer deposition (ALD) is usually used to deposit $\mathrm{Al}_{2} \mathrm{O}_{3}$ as a gate dielectric in MOSFETs. In general, a pre-treatment is very important to clean the top poor-quality $\mathrm{GaN}$ layer with the native oxidation and impurities that cause high-density interface states $\left(>10^{12} \mathrm{~cm}^{-2} \mathrm{eV}^{-1}\right)$ because of the insufficient chemical bonds during the forming process of $\mathrm{Al}_{2} \mathrm{O}_{3}$. Many attempts have been done to prepare good $\mathrm{GaN}$ surfaces for $\mathrm{ALD}-\mathrm{Al}_{2} \mathrm{O}_{3}$ deposition [24-27]. Usually, acid cleaning is used to remove the native oxidized layer and impurities in GaN-capacitors. However, during the complicated fabrication process of GaN-MOSFETs prior to the deposition of dielectric layers, $\mathrm{p}-\mathrm{GaN}$ channels contain significant damages and defects, thus resulting in higher surface state density than that of general GaN-capacitors. This indicates an essential necessity for an alternative surface treatment processing for GaN-MOSFETs fabrication.

To solve the above issues, we fabricated n-channel GaN-MOSFETs by both implantation and regrowth methods. For the first time, the inversion-mode GaN-MOSFETs are fabricated with regrown $\mathrm{p}$-GaN layers after forming the epitaxially grown n-GaN layers. In this method, it is expected to minimize the damages on the vulnerable $\mathrm{p}-\mathrm{GaN}$ layer during the complicated fabrication process. The traditional implantation technique is also used to fabricate n-channel GaN-MOSFETs and compared with the proposed regrowth method. Additionally, the semiconductor surface treatments using the combination of physical and chemical treatments prior to the dielectric deposition have been conducted to reduce the trapped charge density. The ozone oxidation technique is used to form the sacrificial $\mathrm{GaO}_{\mathrm{x}}$ on the $\mathrm{GaN}$ film, which is subsequently removed by wet etchings. Therefore, the damaged GaN layer consisting of undesired defects during the fabrication process would be partly avoidable. As a result, the MOSFETs with the regrown $\mathrm{p}-\mathrm{GaN}$ gate body show the superior properties over the other devices fabricated using the implantation method. According to our knowledge, the on/off ratio $\left(\mathrm{I}_{\mathrm{on}} / \mathrm{I}_{\text {off }}\right)$ of approximately $4 \times 10^{7}$ obtained in this work is one of the best results to date. 


\section{Experimental}

The fabrication of the GaN-MOSFET structure with the implantation technique starts with the $500 \mathrm{~nm}$-thick homoepitaxial Mg-doped p-GaN $\left(2 \times 10^{17} \mathrm{~cm}^{-3}\right)$ layer grown by MOCVD on a free standing GaN substrate consisting of a thin unintentionally doped GaN (UID- GaN) and high-resistance insulation GaN substrate, as shown in Figure 1a. The $\mathrm{SiO}_{2}$ hard mask is deposited on the top of the free standing GaN structure using the plasma enhanced chemical vapor deposition (PECVD) with tetraethyl orthosilicate and oxygen. Subsequently, mesa structures are defined using the conventional lithography and wet etching of the $\mathrm{SiO}_{2}$ hard mask. The GaN mesa-insulation regions are formed using $\mathrm{Cl}_{2} / \mathrm{BCl}_{3}$ reactive-ion etching, as shown in Figure $1 \mathrm{~b}$. The $\mathrm{SiO}_{2}$ hard mask is removed using the buffered hydrofluoric (BHF) acid. Subsequently, the source and drain (S/D) regions are implanted with Si atoms at room temperature with $10 \mathrm{~nm}$-thick $\mathrm{SiO}_{\mathrm{x}} \mathrm{N}_{\mathrm{y}}$ and photoresist protection layer on the gate regions, as shown in Figure 1c. The implantation energy is $15 \mathrm{keV}$ and the dose implantation is $10^{15} \mathrm{~cm}^{-2}$. The rapid thermal annealing (RTA) in the $\mathrm{N}_{2}$ atmosphere at $100{ }^{\circ} \mathrm{C}$ is used to activate the dopants after the implantation. For the GaN-MOSFET structure fabricated by the regrowth method, the fabrication process is based on the $\mathrm{n}-\mathrm{GaN}\left(3 \times 10^{18} \mathrm{~cm}^{-3}\right)$, as shown in Figure 2a. The GaN mesa-insulation regions and $n-G a N$ layer on the gate-body region are etched using the reactive-ion etching with $\mathrm{Cl}_{2} / \mathrm{BCl}_{3}$ gas mixture, as shown in Figure $2 b, c$. The sample is immerged in the tetramethyl ammonium hydroxide (TMAH) with $10 \mathrm{wt} \%$ at $70{ }^{\circ} \mathrm{C}$ in $5 \mathrm{~min}$ to etch the damaged $\mathrm{n}-\mathrm{GaN}$ on the vertical side because of the reactive-ion etching. Subsequently, $200 \mathrm{~nm}$-thick $\mathrm{Mg}$-doped p-GaN $\left(2 \times 10^{17} \mathrm{~cm}^{-3}\right)$ is selectively regrown on the gate region. The regrown $\mathrm{p}-\mathrm{GaN}$ layer is formed using trimethylgallium (TMGa), bis (cyclopentadienyl) magnesium $\left(\mathrm{Cp}_{2} \mathrm{Mg}\right)$, and $\mathrm{NH}_{3}$ as precursors at $950^{\circ} \mathrm{C}$. The growth is performed with the $\mathrm{NH}_{3}$ flux of $10 \mathrm{slm}$ and TMGa flux of $20 \mathrm{sccm}$. An ozone oxidation at $300{ }^{\circ} \mathrm{C}$ is used to form the sacrificial $\mathrm{GaO}_{x}$ of the damaged $\mathrm{GaN}$ layer, which is subsequently removed using $\mathrm{BHF}$ acid. The treatment of forming and removing the sacrificial $\mathrm{GaO}_{x}$ layer is repeated two times and re-cleaned using diluted hydrofluoric (DHF) acid and $\mathrm{HCl}$ acid with the concentration of $0.8 \mathrm{M}$ (mole/litter). The $28 \mathrm{~nm}$-thick $\mathrm{Al}_{2} \mathrm{O}_{3}$ thin film as a dielectric is deposited using PEALD with trimethylaluminum and oxygen plasma, as shown in Figures $1 \mathrm{~d}$ and $2 \mathrm{~d}$. According to previous studies, the $\mathrm{Al}_{2} \mathrm{O}_{3}$ thin film transforms from amorphous to crystalline phase at over $800{ }^{\circ} \mathrm{C}$ [28]. Therefore, $\mathrm{Al}_{2} \mathrm{O}_{3}$ dielectric is annealed at $700{ }^{\circ} \mathrm{C}$ in a nitrogen $\left(\mathrm{N}_{2}\right)$ ambience for 1 minute using the rapid temperature annealing (RTA) technique. The electron beam evaporation and conventional wet etching methods are used to form the Ni gate electrodes. The Ti/Al stack structure is formed on the S/D regions by the lift-off technique and subsequently treated with the metallization annealing (PMA) at $600{ }^{\circ} \mathrm{C}$ in a $\mathrm{N}_{2}$ ambience to obtain the ohmic contact, as shown in Figures 1e and 2e. The top view of the fabricated MOSFETs is shown in Figure $2 \mathrm{f}$.

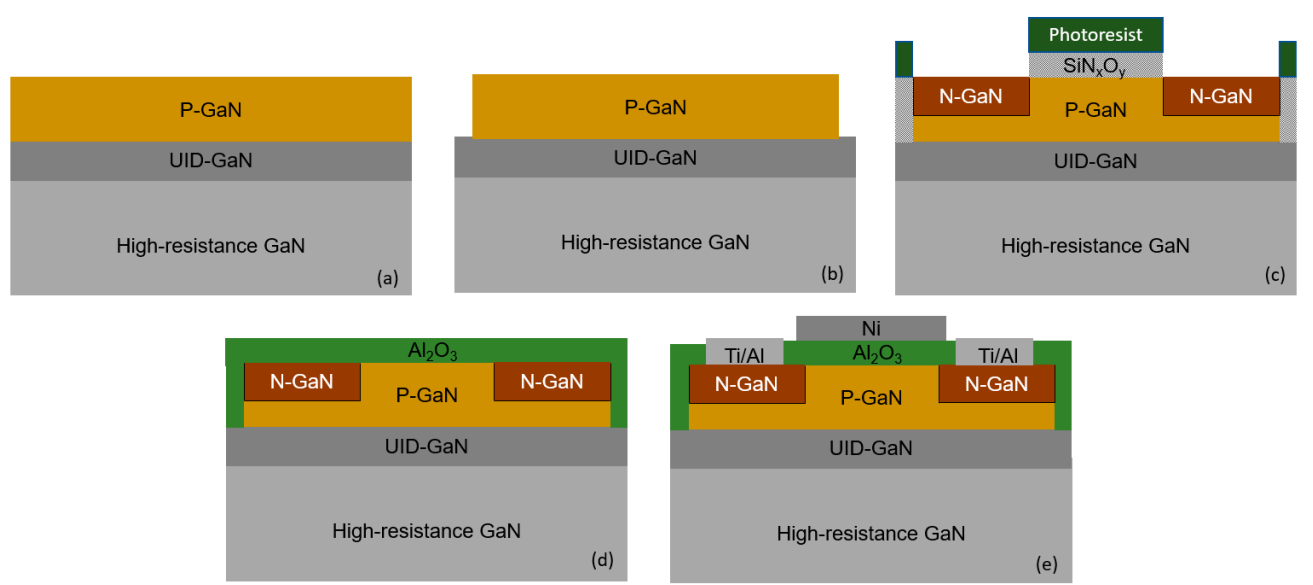

Figure 1. Fabrication process of the gallium nitride-metal-oxide field-effect transistors (GaN-MOSFETs) fabricated using the implantation technique. (a) p-GaN grown on a free standing GaN substrate, (b) mesa structure, (c) implantation of $\mathrm{Si}$ atoms, (d) $\mathrm{Al}_{2} \mathrm{O}_{3}$ deposition, (e) contact deposition and annealing. 

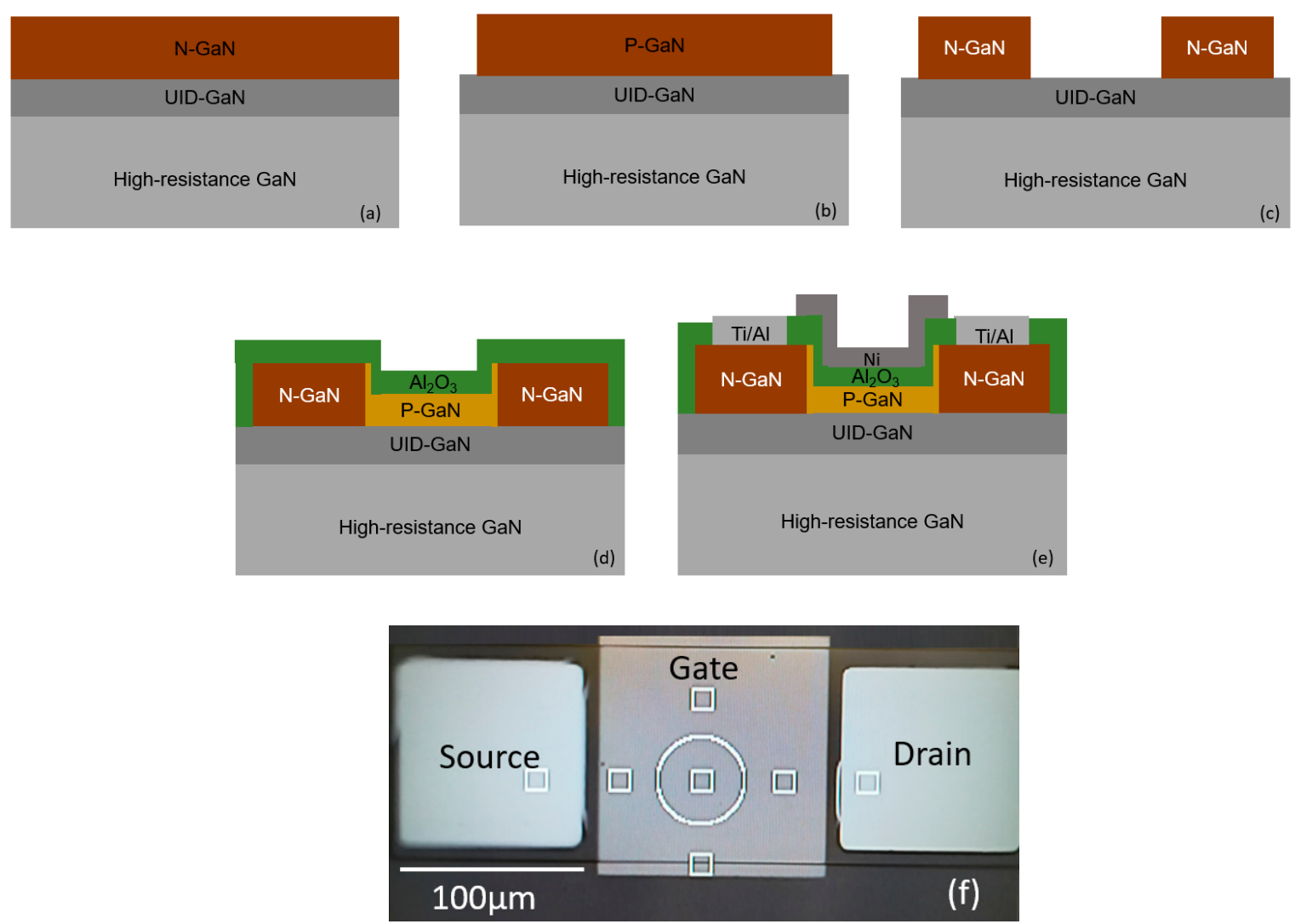

Figure 2. Fabrication process of the gallium nitride-metal-oxide field-effect transistors (GaN-MOSFETs) fabricated using the regrowth method. (a) n-GaN grown on a free standing GaN substrate, (b) mesa structure, (c) etching $\mathrm{n}-\mathrm{GaN}$ layer on the gate-body region, (d) regrowth of $\mathrm{p}-\mathrm{GaN}$ and $\mathrm{Al}_{2} \mathrm{O}_{3}$ deposition, (e) contact deposition and annealing, (f) the top view of the fabricated MOSFETs.

\section{Results and Discussion}

According to the previous studies, interface state densities $\left(D_{i t}\right)$ of approximately $10^{12} \mathrm{~cm}^{-2} \mathrm{eV}^{-1}$ and higher are observed in the GaN-MOS capacitors without the surface treatment [29,30]. Because GaN cannot be formed with an oxides-free pristine interface, pre-deposition surface treatments are crucial for a good nucleation of dielectric layers. An erratic nucleation can lead to the formation of such defects as vacancies, vacancy-complexes, interstitials, etc., resulting in high densities of interface traps and fixed charges. By using the proposed treatment process, a low $D_{i t}$ can be obtained because of the removal of nitrogen vacancy $\left(N_{v}\right)$, Ga dangling bonds, and damages on the surface of GaN layer. As a result, the surface trapped state density of approximately $10^{11} \mathrm{~cm}^{-2} \mathrm{eV}^{-1}$ is obtained in our previous work [31]. This value is low enough to satisfy the operation of general MOSFETs.

Two types of GaN-MOSFETs fabricated with different techniques are evaluated and compared. Figure 3 shows the output current-voltage $\left(I_{d}-V_{d}\right)$ characteristics of the GaN- MOSFETs with the channel length and channel width of $100 \mu \mathrm{m}$. It has been observed that the drain currents are effectively controlled by the gate voltages, thus confirming the transistor operation. Both devices operate with the normally off (enhancement-mode) function. Additionally, the maximum saturation source-drain current of the GaN-MOSFET fabricated using the regrowth method is higher than that of the implantation technique, revealing the low on-state resistance and high electron mobility. 

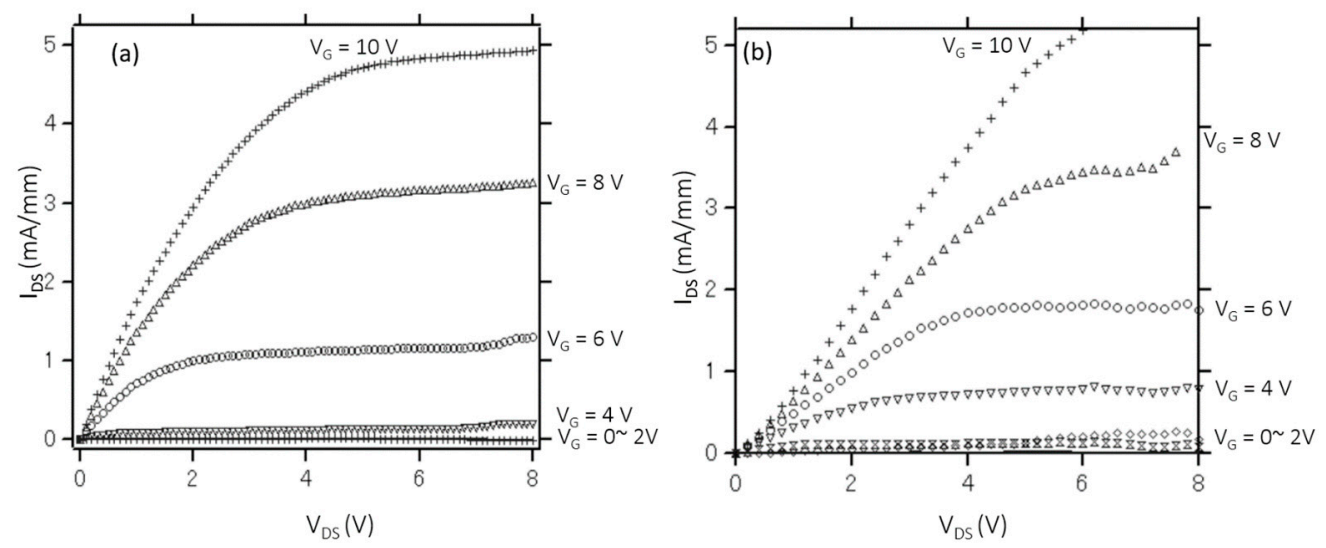

Figure 3. Output current-voltage $\left(\mathrm{I}_{d}-\mathrm{V}_{\mathrm{d}}\right)$ characteristics of GaN-MOSFETs fabricated using the implantation technique (a) and regrowth method (b).

The logarithmic plots of the drain current - gate voltage $\left(\mathrm{I}_{\mathrm{d}}-\mathrm{V}_{\mathrm{g}}\right)$ transfer characteristics under the drain-to-source voltage of $50 \mathrm{mV}$ at a room temperature are shown in Figure 4. The threshold voltages of the devices fabricated by the regrowth and ion implantation methods extracted from the gate bias intercept of the linear extrapolation $\mathrm{I}_{\mathrm{d}}$ are approximately 1.6 and $2.0 \mathrm{~V}$, respectively. Additionally, the leakage current below the pinch-off voltage in the MOSFET fabricated using the regrowth method is roughly 4 orders of magnitude better than that of the ion implantation technique. This behavior might be explained as the influence of damages after the ion implantation process. During the implantation process, it is difficult to control defect states although the post deposition annealing (PDA) process can partly release this undesired behavior. According to the previous discussions, there is a possibility that defect states play a role of donors in $\mathrm{p}-\mathrm{GaN}$ and thus dominating the off-state currents. The high leakage current might be caused by the defects, dislocation, and trapped electrons that create the sub-threshold channel in the off-region. Additionally, the subthreshold slope of device fabricated using the regrowth method is approximately $300 \mathrm{mV} / \mathrm{dec}$, which is better than that of the device fabricated by the ion implantation technique $(\sim 500 \mathrm{mV} / \mathrm{dec})$. This difference is also related to the drain leakage current of the implanted device as a previous discussion. It can be concluded that it is possible to reduce the damages on $\mathrm{p}-\mathrm{GaN}$ layer during the fabrication process by using the fabrication process based on the regrowth method. Therefore, the off-state current is much lower than that of the device fabricated by the implantation technique. The performances of regrown devices in this work are better than the previous inversion-channel GaN MOSFETs using $\mathrm{MgO}$ and $\mathrm{SiN}_{\mathrm{x}}$ and other $\mathrm{Al}_{2} \mathrm{O}_{3}$ dielectrics $[5,18,32,33]$. According to our knowledge, the $\mathrm{I}_{\mathrm{on}} / \mathrm{I}_{\text {off }}$ ratio of approximately $4 \times 10^{7}$ obtained in this work is one of the best results to date.

Figure $5 \mathrm{a}, \mathrm{b}$ shows the plots for the Y-function and transconductance of the MOSFETs fabricated using the implantation technique and regrowth method, respectively. The comparisons of the transconductance and Y-function of two devices are shown in Figure 6a,b, respectively. According to Figure $6 \mathrm{a}$, the transconductance of the device fabricated by the regrowth method is larger than that of the implantation technique. Moreover, the threshold voltages of the implanted GaN-MOSFET and regrown GaN-MOSFET extracted from the Y-function are approximately 1.8 and $2.2 \mathrm{~V}$, respectively, indicating a good $\mathrm{p} / \mathrm{n}-\mathrm{GaN}$ junction in the device fabricated by the regrowth method. These values are slightly higher than those extracted from the gate-bias intercept of the linear extrapolation of $I_{d}$ in the $I_{d}-V_{g}$ characteristic. The minor difference of threshold voltages between two extraction methods is considered to be due to the fitting error. In general, the selectively etched and regrown p-GaN channel is expected to enhance the drain current, channel electron mobility, and reduce the series resistance by reducing the damages on $\mathrm{p}-\mathrm{GaN}$ channels. Although the gate channel of the implanted MOSFET is fully covered by $\mathrm{SiN}_{\mathrm{x}} \mathrm{O}_{\mathrm{y}}$ and photoresist during the Si-implantation process, it is suggested that some Si atoms still penetrate the $\mathrm{p}-\mathrm{GaN}$ layer. Moreover, during the fabrication process, the $\mathrm{p}-\mathrm{GaN}$ layer is exposed in the plasma environment, high temperature activation annealing $\left(\sim 1000^{\circ} \mathrm{C}\right)$, resulting 
in many defects in the structure. Therefore, the channels of MOSFET fabricated using the regrowth method are expected to possess more extensive $\mathrm{p} / \mathrm{n}$ junction than those of the MOSFET fabricated using the implantation technique. In contrast, because of the defects, electrons diffusing and/or contaminating in the $\mathrm{p}-\mathrm{GaN}$ layer of the device fabricated by the implantation technique, the devices investigated in this work do not only utilize the channel inversion as usual inversion- mode MOSFETs but also the electron accumulation formed at the surface of the damaged $\mathrm{p}-\mathrm{GaN}$ layer. Since there are defects and electrons trapped in the structure, the drain current is not only controlled by adjusting the gate bias and interface conditions, but also the amount of the subthreshold carriers. From above discussions, it is shown that the GaN-MOSFETs fabricated using the regrowth method perform superior characteristics of threshold voltage, on-state current, transconductance, and subthreshold behaviors over the other relative devices fabricated using the ion implantation technique. The comparison of $\mathrm{I}_{\mathrm{on}} / \mathrm{I}_{\text {off }}$ ratios obtained in this work and previous reports is shown in Figure 7 [32-35]. It is concluded that the $\mathrm{I}_{\mathrm{on}} / \mathrm{I}_{\text {off }}$ ratio of GaN-MOSFETs can be optimized using the regrowth and surface treatment techniques proposed in this work.

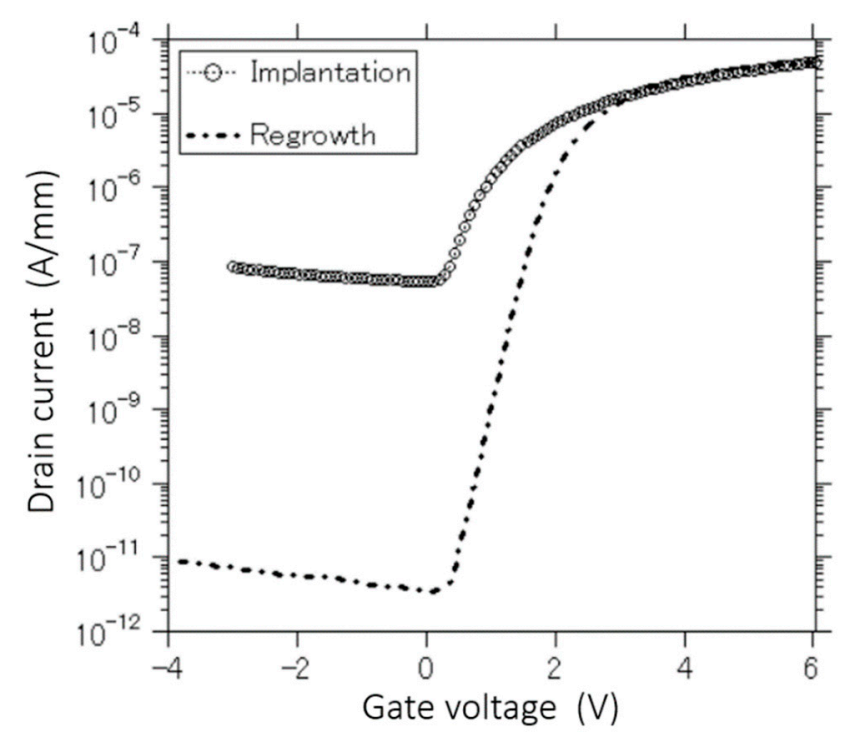

Figure 4. Transfer $I_{d}-V_{g}$ characteristics.
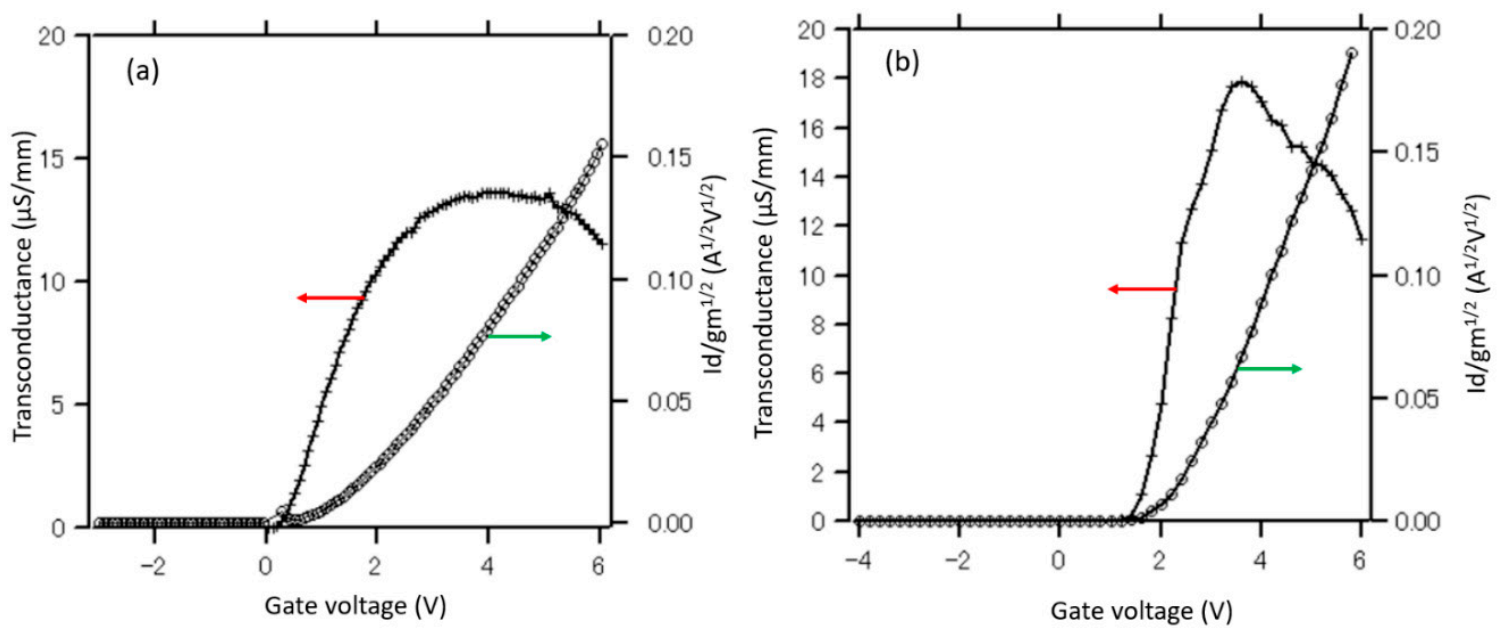

Figure 5. Y-function and transconductance of MOSFETs fabricated using the ion implantation technique (a) and regrowth method (b). 

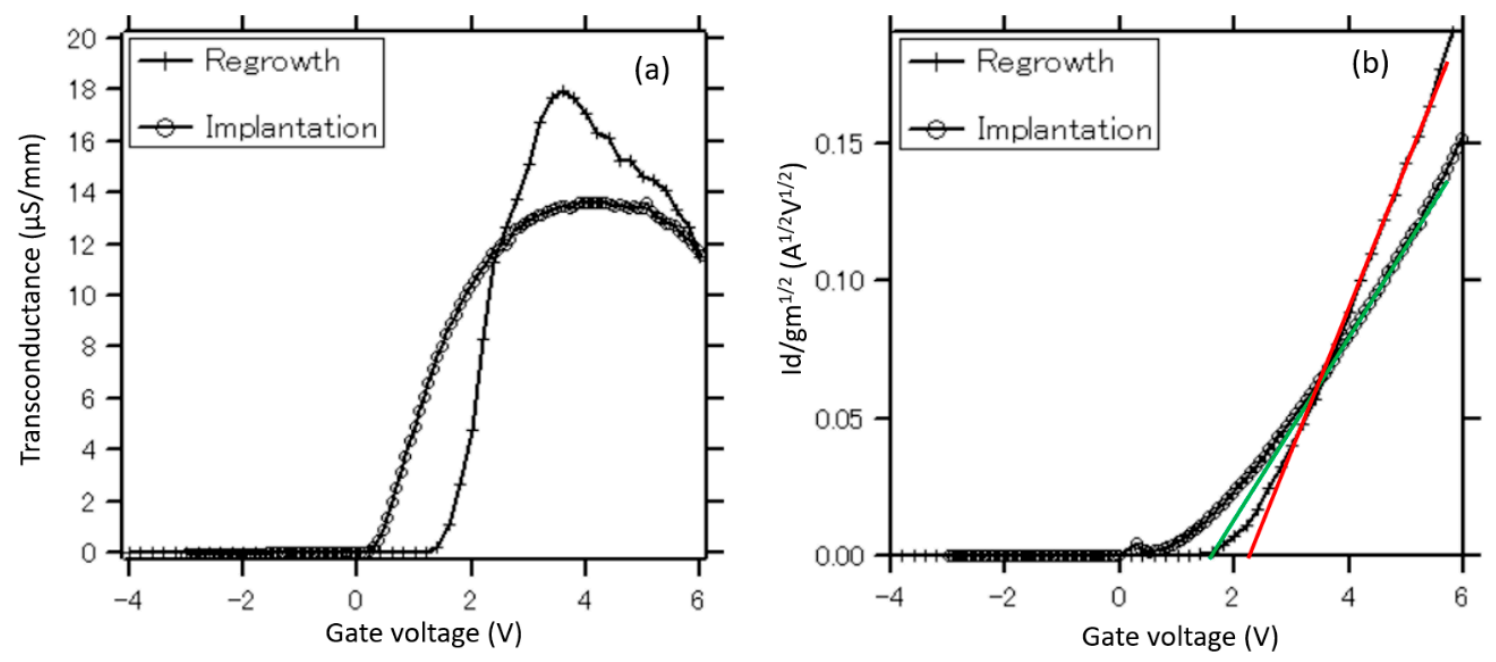

Figure 6. Comparison of transconductances (a) and threshold voltages (b) extracted from Y-function of two types of MOSFETs.

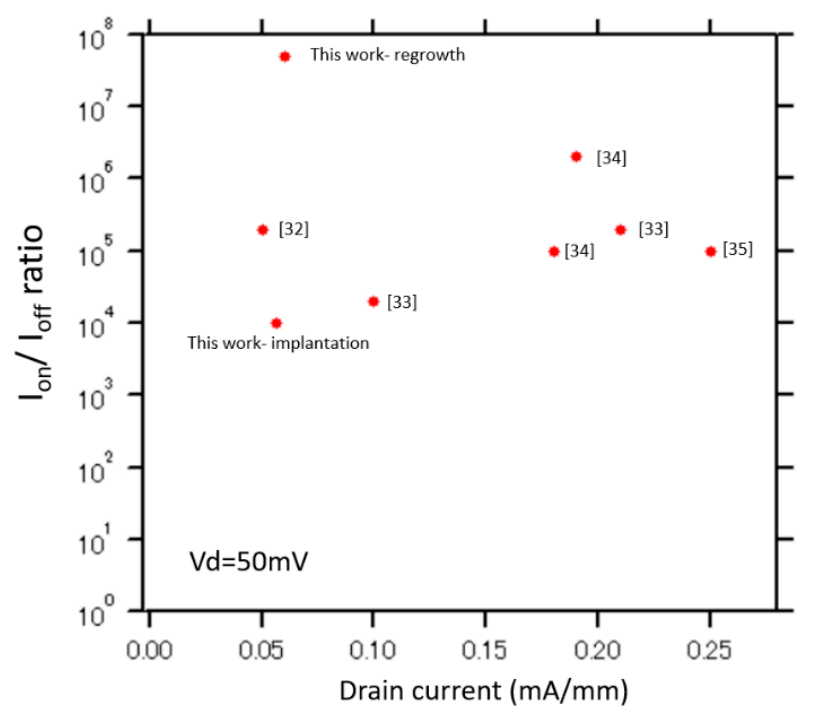

Figure 7. Comparison of $\mathrm{I}_{\mathrm{on}} / \mathrm{I}_{\mathrm{off}}$ ratios obtained in this work and previous reports.

Figure 8 shows the effective channel-electron mobility of fabricated GaN-MOSFETs. The effective electron mobilities are extracted from the Id-Vg characteristics measured in the dark room. The electron mobilities obtain the maximum values at the specific applied bias gate voltages before decreasing with the increase of carriers density because of the increase of the applied gate voltages. This is the evidence of the appearance of the Coulomb scattering centers. Additionally, the maximum mobility of $120 \mathrm{~cm}^{2} / \mathrm{V} \cdot \mathrm{s}$ in the regrown MOSFET is higher than that $\left(100 \mathrm{~cm}^{2} / \mathrm{V} \cdot \mathrm{s}\right)$ of the implanted MOSFET. Because of the damages caused by the implantation and other fabrication steps, the p-GaN layer can contain defects, trapped electrons, ionized impurities, etc. Impurity scattering derived from the charged particles caused by those undesired behaviors would make the electron mobility in the channel formed at the GaN-surface considerably lower than that of a normal bulk GaN. Matthiessen's rule has shown many factors deciding the channel mobility, such as Coulomb scattering mobility, surface phonon mobility, bulk mobility, and surface roughness mobility. Regarding the influence of interface charges near the MOS interface on the channel electron mobility, a significant mobility degradation is observed in Si-MOSFETs with the interface state density of over $10^{12} \mathrm{~cm}^{-2} \mathrm{eV}^{-1}$ [36]. According to the Terman method, the interface state density for the fabricated devices is approximately $10^{11} \mathrm{~cm}^{-2} \mathrm{eV}^{-1}$. Therefore, it is expected that the mobility of the MOS channel region will be comparable to the bulk 
GaN's mobility. A bulk mobility of approximately $600 \mathrm{~cm}^{2} / \mathrm{V} \cdot \mathrm{s}$ at room temperature has been reported for $n$-doped bulk GaN with $\mathrm{N}_{\mathrm{d}}=3 \times 10^{17} \mathrm{~cm}^{-3}$ [37]. However, although the interface trapped density obtained in this work is low enough for general MOSFETs, the maximum inversion electron mobility is five times lower than that of the bulk GaN. Therefore, it seems that the low channel mobility in GaN-MOSFETs is mainly attributed by GaN crystallinity and/or coexistence of carriers originated from defect states rather than the oxide and/or interface trapped states. It is expected that higher hole mobilities can be achieved by further improvement of the MOSFETs processing and p-GaN quality.

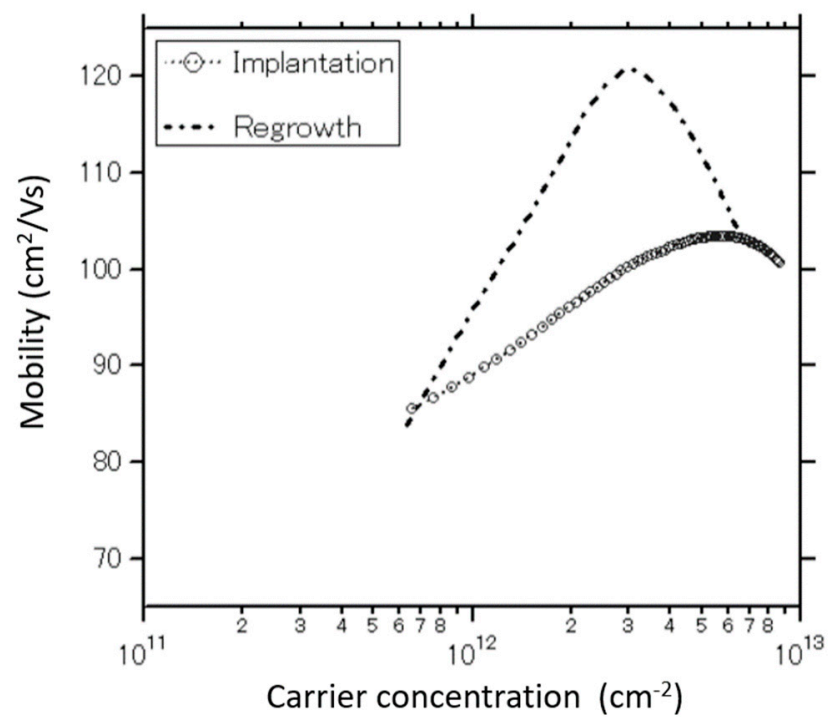

Figure 8. Electron mobilities in MOSFETs fabricated using the regrowth and implantation method.

\section{Conclusions}

In this work, we have fabricated and evaluated many MOSFET devices based on homoepitaxial GaN using two methods of the selective area regrowth and ion implantation. For the implantation method, the source and drain regions are implanted with $\mathrm{Si}$ atoms with $10 \mathrm{~nm}$-thick $\mathrm{SiO}_{\mathrm{x}} \mathrm{N}_{\mathrm{y}}$ and photoresist protection layer on the gate regions. For the regrown method, the gate is completely removed and regrown after making the source and drain regions to minimize damages on the gate. Moreover, the semiconductor surface treatments using the combination of physical and chemical treatments prior to the dielectric deposition have been proposed for the GaN-MOSFET's fabrication to reduce the trapped charge density. As a result, all characteristics of MOSFETs fabricated using the regrowth method are better than those of the relative devices fabricated using the ion implantation technique. The electron mobility, transconductance, and subthreshold values in GaN-MOSFETs based on implantation technique are $100 \mathrm{~cm}^{2} / \mathrm{V} \cdot \mathrm{s}, 14 \mu \mathrm{s} / \mathrm{mm}, 500 \mathrm{mV} / \mathrm{dec}$, respectively. Meanwhile, the GaN-MOSFETs fabricated using the regrowth method perform the electron mobility, transconductance, and subthreshold of $120 \mathrm{~cm}^{2} / \mathrm{V} \cdot \mathrm{s}, 18 \mu \mathrm{s} / \mathrm{mm}, 300 \mathrm{mV} / \mathrm{dec}$, respectively. The MOSFETs with the regrown $\mathrm{p}-\mathrm{GaN}$ gate body show the $\mathrm{I}_{\mathrm{on}} / \mathrm{I}_{\text {off }}$ ratio of approximately $4 \times 10^{7}$, which is, to our knowledge, among the best results of GaN-MOSFETs to date. This investigation provides a valuable information for the future work on GaN-MOSFETs for applications of high-power switching devices.

Author Contributions: Experimentation design, writing, review and editing, H.T.N.; Experimentation design of MOCVD, H.Y., T.T.; Scientific discussion, T.Y., M.S. All authors have read and agree to the published version of the manuscript.

Acknowledgments: This work is partly supported by New Energy and Industrial Technology Development Organization (NEDO)_Japan. A part of this work is conducted at the AIST NPF, supported by "Nanotechnology Platform Program" of Japanese Ministry of Education, Culture, Sports, Science and Technology (MEXT). Also, the authors would like to thank Noriyuki Taoka in Nagoya University for his fruitful discussion.

Conflicts of Interest: The authors declare no conflict of interest. 


\section{References}

1. Roccaforte, F.; Giannazzo, F.; Iucolano, F.; Eriksson, J.; Weng, M.H.; Raineri, V. Surface and interface issues in wide band gap semiconductor electronics. Appl. Surf. Sci. 2010, 256, 5727-5735. [CrossRef]

2. Saito, W.; Takada, Y.; Kuraguchi, M.; Tsuda, K.; Omura, I. Recessed-gate structure approach toward normally off high-Voltage AlGaN/GaN HEMT for power electronics applications. IEEE Electron Device Lett. 2006, 53, 356-362. [CrossRef]

3. Uemoto, Y.; Hikita, M.; Ueno, H.; Matsuo Ishida, H.; Yanagihara, M.; Ueda, T.; Tanaka, T.; Ueda, D. Gate Injection Transistor (GIT) - A Normally-Off AlGaN/GaN Power Transistor Using Conductivity Modulation. IEEE Trans. Electron Devices 2007, 54, 3393-3399. [CrossRef]

4. Hwang, I.; Kim, J.; Choi, H.S.; Choi, H.; Lee, J.; Kim, K.Y.; Park, J.-B.; Lee, J.C.; Ha, J.; Oh, J.; et al. p-GaN Gate HEMTs With Tungsten Gate Metal for High Threshold Voltage and Low Gate Current. IEEE Electron Device Lett. 2013, 34, 202. [CrossRef]

5. Irokawa, Y.; Nakano, Y.; Ishiko, M.; Kachi, T.; Kim, J.; Ren, F.; Gila, B.P.; Onstine, A.H.; Abernathy, C.R.; Pearton, S.J.; et al. $\mathrm{MgO} / \mathrm{p}-\mathrm{GaN}$ enhancement mode metal-oxide semiconductor field-effect transistors. Appl. Phys. Lett. 2004, 84, 2919. [CrossRef]

6. Huang, W.; Khan, T.; Chow, T.P. Enhancement-Mode n-Channel GaN MOSFETs on p and n-GaN/Sapphire Substrates. IEEE Electron Device Lett. 2006, 27, 796. [CrossRef]

7. Otake, H.; Egami, S.; Ohta, H.; Nanishi, Y.; Takasu, H. GaN-Based Trench Gate Metal Oxide Semiconductor Field Effect Transistors with Over $100 \mathrm{~cm}^{2} /(\mathrm{V} \mathrm{s})$ Channel Mobility. Jpn. J. Appl. Phys. 2007, 46, L599-L601. [CrossRef]

8. Kodama, M.; Sugimoto, M.; Hayashi, E.; Soejima, N.; Ishiguro, O.; Kanechika, M.; Itoh, K.; Ueda, H.; Uesugi, T.; Kachi, T. GaN-Based Trench Gate Metal Oxide Semiconductor Field-Effect Transistor Fabricated with Novel Wet Etching. Appl. Phys. Express 2008, 1, 021104. [CrossRef]

9. Otake, H.; Chikamatsu, K.; Yamaguchi, A.; Fujishima, T.; Ohta, H. Vertical GaN-Based Trench Gate Metal Oxide Semiconductor Field-Effect Transistors on GaN Bulk Substrates. Appl. Phys. Express 2008, 1, 011105. [CrossRef]

10. Niiyama, Y.; Ootomo, S.; Li, J.; Nomura, T.; Kato, S.; Chow, T.P. Normally off operation GaN-based MOSFETs for power electronics applications. Semicond. Sci. Technol. 2010, 25, 125006. [CrossRef]

11. Kambayashi, H.; Satoh, Y.; Kokawa, T.; Ikeda, N.; Nomura, T.; Kato, S.; Teramoto, A.; Sugawa, S.; Ohmi, T. High Power Normally-Off GaN MOSFET. ECS Trans. 2011, 41, 87.

12. Trung, N.H.; Taoka, N.; Yamada, H.; Takahashi, T.; Yamada, T.; Shimizu, M. Experimental Demonstration of n- and p-channel GaN-MOSFETs toward Power IC Applications. ECS J. Solid State Sci. Technol. 2020, 9, 015001. [CrossRef]

13. Takashima, S.; Ueno, K.; Matsuyama, H.; Inamoto, T.; Edo, M.; Takahashi, M.S.; Nakagawa, K. Control of the inversion-channel MOS properties by Mg doping in homoepitaxial p-GaN layers. Appl. Phys. Express 2017, 10, 121004. [CrossRef]

14. Zhang, K.; Liao, M.; Imura, M.; Nabatame, T.; Ohi, A.; Sumiya, M.; Sang, L. Electrical hysteresis in p-GaN metal-oxide-semiconductor capacitor with atomic-layer-deposited $\mathrm{Al}_{2} \mathrm{O}_{3}$ as gate dielectric. Appl. Phys. Express 2016, 9, 121002. [CrossRef]

15. Chang, Y.C.; Lee, Y.J.; Chiu, Y.N.; Lin, T.D.; Wu, S.Y.; Chiu, H.C.; Kwo, J.; Wang, Y.H.; Hong, M. MBE grown high $\mathrm{k}$ dielectrics $\mathrm{Ga}_{2} \mathrm{O}_{3}\left(\mathrm{Gd}_{2} \mathrm{O}_{3}\right)$ on $\mathrm{GaN}$. J. Cryst. Growth 2007, 301-302, 390-393. [CrossRef]

16. Ren, F.; Hong, M.; Chu, S.N.G.; Marcus, M.A.; Schurman, M.J.; Baca, A.; Pearton, S.J.; Abernathy, C.R. Effect of temperature on $\mathrm{Ga}_{2} \mathrm{O}_{3}\left(\mathrm{Gd}_{2} \mathrm{O}_{3}\right) / \mathrm{GaN}$ metal-oxide-semiconductor field-effect transistors. Appl. Phys. Lett. 1998, 73, 3893. [CrossRef]

17. Chang, Y.C.; Chiu, H.C.; Lee, Y.J.; Huang, M.L.; Lee, K.Y.; Hong, M.; Chiu, Y.N.; Kwo, J.; Wang, Y.H. Structural and electrical characteristics of atomic layer deposited high $\mathrm{k} \mathrm{HfO}_{2}$ on $\mathrm{GaN}$. Appl. Phys. Lett. 2007, 90, 232904. [CrossRef]

18. Saripalli, Y.N.; Pei, L.; Biggerstaff, T.; Ramachandran, S.; Duscher, G.J.; Johnson, M.A.L.; Zeng, C.; Dandu, K.; Jin, Y.; Barlage, D.W. Transmission electron microscopy studies of regrown GaN Ohmic contacts on patterned substrates for metal oxide semiconductor field effect transistor applications. Appl. Phys. Lett. 2007, 90, 204106. [CrossRef] 
19. Yamada, T.; Ito, J.; Asahara, R.; Watanabe, K.; Nozaki, M.; Hosoi, T.; Shimura, T.; Watanabe, H. Improved interface properties of GaN-based metal-oxide-semiconductor devices with thin Ga-oxide interlayers. Appl. Phys. Lett. 2017, 110, 261603. [CrossRef]

20. Sun, M.; Zhang, Y.; Gao, X.; Palacios, T. High-performance GaN vertical fin power transistors on bulk GaN substrates. IEEE Electron Device Lett. 2017, 38, 509-512. [CrossRef]

21. Lee, H.B.; Cho, H.I.; An, H.S.; Bae, Y.H.; Lee, M.B.; Lee, J.H.; Hahm, S.H. A normally off GaN n-MOSFET with Schottky-barrier source and drain on a Si-auto-doped p-GaN/Si. IEEE Electron Device Lett. 2006, 27, 81-83.

22. Kucheyeva, S.O.; Williamsa, J.S.; Pearton, S. Ion implantation into GaN. J. Mater. Sci. Eng. 2001, 33, 51-107. [CrossRef]

23. Neumayer, D.A.; Ekerdt, J.G. Growth of Group III Nitrides. A Review of Precursors and Techniques. Chem. Mater. 1996, 8, 9. [CrossRef]

24. Cico, K.; Kuzmik, J.; Gregusova, D.; Stoklas, R.; Lalimsky, T.; Georgakilas, A.; Pogany, D.; Frohlich, K. Optimization and performance of $\mathrm{Al}_{2} \mathrm{O}_{3} / \mathrm{GaN}$ metal-oxide-semiconductor structures. Microelectron. Reliab. 2007, 47, 790-793. [CrossRef]

25. Chang, Y.H.; Chiu, H.C.; Chang, W.H.; Kwo, J.; Tsai, C.C.; Hong, J.M.; Hong, M. GaN metal-oxidesemiconductor diodes with molecular beam epitaxy- $\mathrm{Al}_{2} \mathrm{O}_{3}$ as a template followed by atomic layer deposition growth. Cryst. Growth 2009, 311, 2084-2086. [CrossRef]

26. Hori, Y.; Mizue, C.; Hashizume, T. Process Conditions for Improvement of Electrical Properties of $\mathrm{Al}_{2} \mathrm{O}_{3} / \mathrm{n}-\mathrm{GaN}$ Structures Prepared by Atomic Layer Deposition. Jpn. J. Appl. Phys. 2010, 49, 080201. [CrossRef]

27. Ostermaier, C.; Lee, H.C.; Hyun, S.Y.; Ahn, S.I.; Kim, K.W.; Cho, H.I.; Ha, J.B.; Lee, J.H. Interface characterization of ALD deposited $\mathrm{Al}_{2} \mathrm{O}_{3}$ on GaN by CV method. Phys. Status Solidi C 2008, 5, 1992-1994. [CrossRef]

28. Kaneki, S.; Ohira, J.; Toiya, S.; Yatabe, Z.; Asubar, J.T.; Hashizume, T. Highly-stable and low-state-density $\mathrm{Al}_{2} \mathrm{O}_{3} / \mathrm{GaN}$ interfaces using epitaxial n-GaN layers grown on free-standing GaN substrates. Appl. Phys. Lett. 2016, 109, 162104. [CrossRef]

29. Hossain, T.; Wei, D.; Edgar, J.H.; Garces, N.Y.; Nepal, N.; Hite, J.K.; Mastro, M.A.; Eddy, C.R.; Meyer, H.M. Effect of GaN surface treatment on $\mathrm{Al}_{2} \mathrm{O}_{3} / \mathrm{n}-\mathrm{GaN}$ MOS capacitors. J. Vac. Sci. Technol. B 2015, 33, 061201. [CrossRef]

30. Long, R.D.; McIntyre, P.C. Surface Preparation and Deposited Gate Oxides for Gallium Nitride Based Metal Oxide Semiconductor Devices. Materials 2012, 5, 1297-1335. [CrossRef]

31. Taoka, N.; Trung, N.H.; Yamada, H.; Takahashi, T.; Yamada, T.; Kubo, T.; Egawa, T.; Shimizu, M. Surface and Bulk Carrier Transports in Accumulation-mode GaN MOSFETs. In Proceedings of the 49th IEEE Semiconductor Interface Specialists Conference 2018, San Diego, CA, USA, 5-8 December 2018.

32. Chang, Y.C.; Chang, W.H.; Chiu, H.C.; Tung, L.T.; Lee, C.H.; Shiu, K.H.; Hong, M.; Kwo, J.; Hong, J.M.; Tsai, C.C. Inversion-channel GaN metal-oxide-semiconductor field-effect transistor with atomic-layer-deposited $\mathrm{Al}_{2} \mathrm{O}_{3}$ as gate dielectric. Appl. Phys. Lett. 2008, 93, 053504. [CrossRef]

33. Kim, D.; Chang, S.; Lee, C.; Bae, Y.; Cristoloveanu, S.; Lee, J.; Hahm, S. Performance of GaN Metal-Oxide-Semiconductor Field-Effect Transistor with Regrown n+-Source/Drain on a Selectively Etched GaN. Jpn. J. Appl. Phys. 2013, 52, 061001. [CrossRef]

34. Kambayashi, H.; Niiyama, Y.; Ootomo, S.; Nomura, T.; Iwami, M.; Satoh, Y.; Sadahiro, K.; Yoshida, S. Normally Off n-Channel GaN MOSFETs on Si Substrates Using an SAG Technique and Ion Implantation. IEEE Electron Device Lett. 2007, 28, 1077-1079. [CrossRef]

35. Niiyama, Y.; Shinagawa, T.; Ootomo, S.; Kambayashi, H.; Nomura, T.; Katos, S. High-power operation of normally-off GaN MOSFETs. Furukawa Rev. 2009, 36, 1-5.

36. Sun, S.C.; Plummer, J.D. Electron mobility in inversion and accumulation layers on thermally oxidized silicon surfaces. IEEE Trans. Electron Devices 1980, 27, 1497-1508. [CrossRef]

37. Schwierz, F. An electron mobility model for wurtzite GaN. Solid-State Electron. 2005, 49, 889-895. [CrossRef]

(C) 2020 by the authors. Licensee MDPI, Basel, Switzerland. This article is an open access article distributed under the terms and conditions of the Creative Commons Attribution (CC BY) license (http://creativecommons.org/licenses/by/4.0/). 